\title{
Effect of hunger drive level on human learning'
}

\author{
ANH K. WOLFGANG2 \\ PENNSYLVANIA STATE UNIVERSITY
}

Two paired-associate leaming experiments, using homogenous and heterogenous lists, tested the $\mathrm{H} \times \mathrm{D}$ theory with hunger manipulated as drive and normative word association strength the index of habit strength. Results showed no significant differences in leaming associated word pairs by Hungry Ss and Control Ss. Consistent, but not statistically significant, evidence was found that, as predicted, Hungry Ss made more errors on competitive pairs than did Control Ss.

In complex learning, Spence (1956, pp. 221-234) hypothesized that the total effective drive (D) operating In an organism combines with habit tendencies (H) aroused by the stimulus situation to produce the particular response which is made. If the dominant response tendency is the correct one, increase in D facllitates performance; if the task involves competing response tendencies, elevation of $D$ strengthens both the correct and competing responses, causing impaired performance.

Spence distinguished two types of $D$, appetitional needs and aversive or emotional drive states (1956, p. 165). Evidence supporting the $H \times D$ theory comes from research in which the form of $D$ manipulated falls in the second category (see Hall, 1966, pp. 164-169; Spence \& Spence, 1966). The present research assessed the effect of level of $D$, defined in terms of number of hours of food deprivation, on learning palred associates in which the dominant $H$ evoked was either the correct response or an incorrect, competing response.

On the basis of the $\mathrm{H} \times \mathrm{D}$ hypothesis, it was predicted that high-D Ss would learn pairs in which the correct response was dominant with fewer errors than would low-D Ss. In the case of word pairs in which a dominant response was incorrect, it was predicted that high-D So would be Inferior to low-D Ss in their performance.

Ss were 112 paid undergraduate men. They were run individually, Hungry $\mathrm{Ss}$ between 4:30 and 6:00 P.M., when they had been without food and drink except water for at least 17-1/2 h and Control Ss between 5:30 and 8:00 P.M., no later than 1-1/2 h after a full meal. In Experiment I, 20 Hungry and 20 Control Ss learned a list of assoclated word pairs and 20 Hungry and 20 Control Ss learned a list of word pairs with high interpair competition. In Experiment $\mathrm{I}, 16$ Hungry and 16 Control Ss learned mixed lists containing both types of pairs.

Four lists of 14 pairs, each list having the same stimulus words, were used. The 1964 Palermo-Jenkins word association norms for undergraduate men were the source of all words. Stimulus words were nouns, none of which had the same initial letter or final three letters in common. List I, consisting of associated stimulus-response pairs, and List II, made up of competitive word pairs, were used in Experiment I. Lists III and IV were constructed using seven of each type of pair in each list. These mixed lists were employed in Experiment $\boldsymbol{H}$. The mean associative strength, according to norms, of the pairs in List I was 2.1\%. The mean associative strength of the assoctated pairs in the mixed lists was $1.8 \%$ (List III) and $2.5 \%$ (List IV). There was no known association between the pairs comprising List II or the competitive pairs in the mixed lists. Response competition was achieved by having the primary free association response as the correct response for a stimulus word in the list other than its natural language associate.

Standard anticipation paired-associate learning procedure was followed. Lists were presented for 15 trials on a Lafayette Model 303A memory drum at a 2:2 sec rate with a 4-sec intertrial interval.

Resulis

Experiment I. A Type 3 (Lindquist, 1953) analysis of variance was performed on the errors made during the 15 trials on the homogeneous lists. Trials was the within-Ss variable and Pairs (associated and competitive) and Drive (Hungry and Control Ss) were between-Ss variables. The main effects of Trials and Pairs were signiflcant beyond the .001 level ( $F=$ 499.92, df =14/1064 for Trials; $F=285.10$, df $=1 / 76$ for Pairs), reflecting the fact that associated pairs were easier than competitive pairs and that learning occurred. The Trials by Pairs interaction was signiflcant beyond the .001 level ( $F=80.95$, df $=14 / 1064$ ), indicating that the two types of word pairs were learned at different rates over trials. Curves based on the data for this interaction show that all So learned assoclated pairs quickly; while errors made on competitive pairs decreased slowly over trials.

It had not been predicted that the main effect of Drive or the Drive by Trials interaction would necessarily be significant because an interaction between D-level and pair type was expected. However, contrary to $H \times D$ theory, neither the interaction of Drive by Pairs or the triple interaction of Drive by Pairs by Trials reached an acceptable level of significance. Apparently Hungry and Control Ss showed the same differential rates of learning associated and competitive pairs.

Experiment II. The data for both mixed lists were combined for analysis because $t$ tests of differences between mean errors by Hungry and Control Ss for 
the two lists revealed no significant differences in learning them.

A Type 6 (Lindquist, 1953) analysis of variance was applied to the errors made on the 15 trials of the mixed lists with Drive (Hungry and Control Ss) the between-Ss factor and Pairs (associated and competitive) and Trials within-Ss factors. Most of the results were in harmony with those obtained in Experiment I. Again contrary to prediction, the Pairs by Drive interaction did not reach statistical significance. However, the triple interaction of Trials by Pairs by Drive was significant beyond the .025 level $(F=2.11$, df $=14 / 420)$. Curves based on this data show that on Trial 2, at the beginning of learning, Hungry Ss made more errors than did Control Ss on both types of pairs. From Trials 3 to 15, the curves of the two D-groups are almost identical for associated pairs, with errors nearly eliminated by Trial 5 . Competitive pairs were learned more slowly by both groups. Except for Trial 3, Hungry Ss made consistently more errors than Control Ss, as the H X D theory predicted.

Further statistical analysis did not uncover further support for the theory. When $t$ tests were applied to the differences in mean errors by Hungry and Control Ss on successive blocks of five trials for each type of pair, none of the differences reached significance. Similarly, when a Type 1 (Lindquist, 1953) analysis of variance was performed on the errors made on the competitive pairs of the mixed lists, nelther the main effect of Drive nor the Trials by Drive interaction proved to be significant.

Discussion

The results of the present research suggest that the associated word pairs, rather than being learned more readily by Hungry than by Control Ss as the $H \times D$ theory predicted, were learned at virtually the same, very rapld, rate by all Ss. Apparently, in spite of the relatively low associative strengths of the pairs used, learning them was an easy task with little opportunity to make errors. As predicted, Hungry Ss made more errors on the competitive pairs than did Control Ss. However, this difference, although consistent, was not significant in any analysis which considered only the effect of D-level on performance or its interaction with Trials.

These results suggest two speculations about the
$H \times D$ hypothesis. It is possible that the $H \times D$ theory describes correctly the relationship of learned responses to aversive or emotional drive, or perhaps simply to anxiety, rather than describing the relationship of such responses to D in general, including appetitive needs. Supporting evidence for the theory obtained in experiments with animals using hunger as $D$ may reflect the anxious or aversive emotional element generated in animals by food deprivation. Such an emotional element probably was not present in voluntary paid human Ss even though they reported feeling hungry.

Alternatively, the results of the present research could indicate that the $\mathrm{H} \times \mathrm{D}$ theory applies to relevant drive, rather than to generalized $D$, which is assumed to be the total effective drive. Spielberger (1966, p. 19) has stated that, viewed as a whole, the experimental evidence points to a reactive, rather than a chronic, effect of anxiety as D on performance. This seems to be another way of saying that D combines multiplicatively with $H$ when the response in question has potential for reducing the level of $D$. Such was not the case in the present studies; learning the paired associates did not reduce hunger as performing a simple task well may reduce anxiety. It is concluded that in the present research, using hunger to manipulate $D$ in human Ss, little support was obtained for the hypothesized multiplicative relationship between generalized D and habit strength.

\section{References}

Hall, J. F. The psychology of learning. Philadelphia: Lippincott, 1966.

Lindquist, E. F. Design and analysis of experiments in psychology and education. New York: Houghton Mifflin, 1953.

Palermo, D. S., \& Jenkins, J. J. Word association norms. Minneapolis: University of Minnesota Press, 1964.

Spence, Janet $T$., \& Spence, $K$. W. The motivational components of manifest anxiety: Drive and drive stimuli. In D. D. Spielberger (Ed.), Anxiety and behavior. New York: Academic Press, 1966. Spence, K. W. Behavior theory and conditioning. New Haven: Yale University Press, 1956.

Spielberger, C. D. (Ed.) Anxiety and behavior. New York: Academic Press, 1966.

\section{Notes}

1. Based on part of a doctoral thesis written under David $\mathbf{S}$. Palermo's direction. Thanks are due him for his able and generous supervision and to George I. Wolfgang for permitting use of the Hartwick College psychological laboratory for the research.

2. Now at State University College, Oneonta, New York. 